\title{
Protección jurídica de los videojuegos a través del derecho de autor
}

\author{
Susana Fernanda Álvarez Cabrera* \\ Katina Yaneth Reyes Hernández"**
}

Recibido: 28 de enero de 2016 • Aprobado: 22 de octubre de 2016

DOI: $10.22395 /$ ojum.v16n3la7

\section{RESUMEN}

La convergencia de elementos creativos como literatura, música, pintura e, incluso, cine en la producción de los videojuegos ha permitido que estos sean el octavo arte en el marco de las industrias creativas. No obstante, una obra de este tipo debe contar con un soporte informático que le permita ser jugada y determinada por el usuario, lo cual aporta un grado de interacción inusual en el resto de creaciones que hacen parte suya. El objetivo central de este trabajo es determinar, mediante una investigación cualitativa, la forma más adecuada de proteger jurídicamente los videojuegos, pues, si bien en el mundo se ha desarrollado una adecuación partiendo de dos grandes vertientes del derecho de autor (el software y las obras multimedia), ambas poseen falencias que podrían ser fácilmente superadas bien sea con la aplicación de una analogía con la obra cinematográfica o mediante la creación de una categoría de obra específica denominada videojuego.

Palabras clave: Videojuegos; propiedad intelectual; protección; software; obras multimedia; obras cinematográficas.

\footnotetext{
Artículo de reflexión producto de investigación en el marco del proyecto "Nuevas dinámicas del derecho privado: desarrollo del derecho de propiedad intelectual en las industrias creativas colombianas", del Grupo de Investigación Conflicto y Sociedad de la Universidad de Cartagena.

* Abogada de la Universidad de Cartagena; joven investigadora del Grupo de Investigación Conflicto y Sociedad; Cartagena, Colombia; susana.alvarez.ca@gmail.com

*. Abogada de la Universidad de Cartagena; joven investigadora del Grupo de Investigación Conflicto y Sociedad; Cartagena, Colombia; katinareyesh@gmail.com
} 


\section{Juridical Protection of Videogames through copyrights}

\section{ABSTRACT}

Convergence of creative elements such as literature, music, painting, and even film in the production of videogames has allowed them to be ranked as the eighth art in the framework of creative industries. However, such a work should hold an information technology support that allows it to be played and set by the user, which implies a degree of unusual interaction in all other creations made part of it. The main objective of this article is to set, through a qualitative research, the most appropriate way of legally protecting videogames; despite an arrangement has been developed worldwide based on two important branches of copyrights (software and multimedia works), both show failures which could be easily repaired either by applying an analogy with cinematographic work or by creating a specific work category known as videogame.

Key words: Videogames; intellectual property; protection; software; multimedia works; cinematographic works. 


\section{INTRODUCCIÓN}

Los elementos creativos empleados para darles vida a los juegos de vídeo son hoy en día de tal complejidad, que trabajar en su producción puede equipararse a una película de Hollywood (Greespan, Boyd, Purewal E Datum, 2013): bandas sonoras interpretadas por orquestas, conceptos visuales, personajes y paisajes creados por diseñadores y artistas gráficos, argumentos y narrativas mucho más intrincadas que la clásica simulación de tenis de Pong, historias donde el jugador toma el papel del personaje principal teniendo la oportunidad de desarrollar su propia trama basada en sus elecciones personales, para así llegar a finales alternativos, y el elemento indispensable: un software soportado por un código informático que permite conjugar todos los elementos para lograr que el juego corra en la consola, ordenador o dispositivo móvil.

Pero ¿por qué preocuparse por saber más acerca de los videojuegos? James Newman (2004) esboza tres razones por las cuales los juegos de vídeo merecen ser tomados en serio: su popularidad; el tamaño de la industria; y la posibilidad de verlos como un modelo de interacción humano-computador. En efecto, este subsector de la economía creativa, que abarca la industria tanto cultural como del conocimiento, ha tenido un impacto significativo en la Contemporaneidad, convirtiéndose en una de las formas más populares de entretenimiento de masas y una de las industrias creativas con mayor crecimiento del mundo, que superan incluso a la del cine y la música (Donaire
E Planells, 2012) y obtiene ganancias multimillonarias que se evidencian en datos como el siguiente:

\begin{abstract}
En las 24 horas siguientes a su publicación en septiembre de 2013, Grand Theft Auto 5 recaudó más de 880 millones de dólares, y se vendieron más de 11 millones de ejemplares en el mundo entero. En un plazo récord de tres días, las ventas alcanzaron los 1000 millones de dólares. A modo de comparación, Iron Man 3, la pelí cula más taquillera del verano de 2013, recaudó 372 millones de dólares, de la venta de billetes en todo el mundo en su primer fin de semana (Greespan, Boyd, E Purewal, 2014, p 11).
\end{abstract}

Sin más, resulta ineludible que los problemas y retos que enfrenta el mundo de los juegos de vídeo, no solo como parte de las industrias creativas en crecimiento, sino como parte de nuestra cultura, sean objeto de estudio en la investigación, máxime cuando desde el derecho se trata de proteger la titularidad de aquellos que hacen posible su existencia.

Esta investigación pretende estudiar la naturaleza jurídica del videojuego para determinar una forma de protección que le resulte adecuada dentro de los regímenes de propiedad intelectual vigentes, tomándole en cuenta como un bien inmaterial único y no como la acumulación de varios tipos de obras. Así se pretende responder el cuestionamiento por una categoría de derecho de autor que haga posible una protección en la que todos los elementos creativos que forman parte 
integral del videojuego como obra sean asociados.

El presente artículo es producto de una investigación jurídica cualitativa, desarrollada en el nivel dogmático, y de tipo analítico documental, en la cual se pretendió concretar una forma de protección eficiente para la creación autoral que son los juegos de vídeo. Las técnicas de recolección de la información estuvieron fundamentadas en el análisis documental, lo cual implica que las fuentes son de carácter secundario, consistentes primordialmente en la revisión de normas, sentencias y textos científicos, información que fue recolectada y organizada usando matrices de datos para luego proceder a su análisis. En tal sentido, las pregunta problema alrededor de la cual se desarrolla la argumentación es: ¿En qué categoría de derecho de autor deben ser encuadrados los videojuegos para obtener una protección que abarque todos los aspectos creativos de la obra?

Para tal efecto analizaremos las categorías donde sería posible encuadrarlos, bien sea software, multimedia, obra cinematográfica u otro tipo de obra de derecho de autor, y en tal caso, cuáles serían las implicaciones en materia de derechos subjetivos y titularidades.

Adicionalmente, teniendo en cuenta la relevancia que este sector de la industria del entretenimiento ha tomado en los mercados contemporáneos, se realizará un análisis comparativo de la tutela jurídica en otros Estados, a saber: Estados Unidos, Japón, Francia y Argentina.

\section{BREVE INTRODUCCIÓN HISTÓRICA}

Sobre el tema de los juegos de vídeo puede hablarse de tres historias paralelas: la de los juegos, la de las consolas, y la de la industria. Estos tres componentes, si bien forman parte de un solo fenómeno (pues no se puede jugar un videojuego sin un aparato que lo soporte y sin un productor y distribuidor), tuvieron sus inicios en décadas distintas.

Ya en 1962 había sido inventado el primer juego de computador de la historia: Spacewar!, creado por el programador y científico Steve Russell del Instituto Tecnológico de Massachusetts (MIT), que en 1971 sería superado por el primer juego arcade de la historia (máquinas de videojuegos con fines recreativos ubicadas en lugares públicos): el Computer Space de Atari, que fue la versión mejorada de Spacewar! creada por Nolan Bushnell, logrando así que paralelamente aparecieran en el mercado las primeras máquinas de videojuegos de arcade.

Aunque Computer Space no tuvo el éxito que se esperaba, quizá porque su complejidad le resultaba intimidante al público de la época (Rabin, 2010), este videojuego hizo que la tecnología, como medio de esparcimiento, saliera de las facultades de Ingeniería y Programación y fuera accesible al público en los Estados Unidos a través de grandes máquinas instaladas en bares y lugares frecuentados por los jóvenes.

En 1972, fue lanzada al mercado la primera consola que les permitiría a los video- 
juegos llegar al entretenimiento casero: la Odyssey de Magnavox, desarrollada por Ralph Baer, que soportaba un solo juego de tenis de mesa que no emitía sonido alguno, pero que sí contaba con un atributo jurídicamente relevante: patentes otorgadas, dando lugar así al primer litigio de patentes sobre videojuegos en el mundo y a la consolidación de una industria, pues la compañía Atari logró generar con su videojuego Pong sumas de dinero exorbitantes, que se imponían al pequeño éxito que había logrado Magnavox con su consola. "Al final, Atari acordó con Magnavox en 1976 por el pago de una licencia única de US\$700.000. Después de eso, Atari fue libre de producir videojuegos sin pagar más dinero a Magnavox" (Rabin, 2010, p 7).

Sin funciones muy intrincadas o historias demasiado trascendentales, soportados en escasos píxeles de color y con fondos negros, ofreciendo formas geométricas simples y con efectos de sonido elementales, se abrió paso a la que se convertiría en una de las industrias más relevantes en el ámbito del entretenimiento global (Ramos, López, Rodríguez, Meng E Abrams, 2013). Esposito (2005), divide la evolución histórica de los juegos de vídeo en cuatro etapas, así:

- De 1971 a 1978: el éxito de los pioneros y el arcade, desde Computer Space en 1971 a Space Invaders en 1978.

- De 1978 a 1983: la época dorada donde se desarrollaron múltiples géneros de juego (deportes, aventura, combate, etc.) y apareció Galaxian en 1979, el primer videojuego en soportar color y Ms. Pac-Man en 1981, el primer juego con una protagonista femenina.

- De 1983 a 1994: evolución de la narrativa, las ideas se hacen más prominentes en términos de la historia que cuenta el juego. Ejemplos de esta nueva generación de videojuegos son: The Legend of Zelda en 1986, Sim City en 1989, y Mario Kart en 1992.

- De 1994 a la actualidad: el auge tecnológico logra hitos como el soporte de gráficos poligonales y una consola que permite correr juegos almacenados en CD-ROM: la PlayStation de Sony. El avance continúa hasta llegar a la actualidad, donde se cuenta con gráficos generados con capturas de movimiento y la interactividad entre usuarios que ofrecen los juegos en línea.

En 1985, surge la Famicon de Nintendo, más adelante rebautizada como Nintendo Entertaintment System (NES), donde corrían dos de los videojuegos más famosos de la historia: Súper Mario Bros y The Legend of Zelda. A partir de ese momento sería la compañía Nintendo, y no Atari, la que dominaría el mercado y se convertiría en sinónimo de videojuegos alrededor el mundo. Casi una década más tarde, en 1995, aparece la PlayStation de Sony en los mercados de América y Europa, y el mundo de los juegos de vídeo vuelve a experimentar un avance colosal: ahora los juegos cuentan con gráficos en 3D almacenados en CD-Rom, no en casetes. Así, podemos sustentar la afirmación de 
Melissinos (citado por Jewel, 2012) en cuanto a que los videojuegos han dado, en apenas unas cuantas décadas, "un salto equivalente a pasar del arte rupestre al impresionismo".

El grado de interacción y realismo, y la minuciosidad presente en los fascinantes universos de los videojuegos actuales poco o nada tienen que ver con los alienígenas toscos en forma de píxeles que aparecían en videojuegos clásicos como Space Invaders o Pac-Man. Hoy en día, los videojuegos constituyen una amalgama de formas tradicionales de arte (música, narración, escultura, pintura) que son reconocidos cada vez más como expresión artística de pleno derecho. (Jewel, 2012)

El grado de desarrollo contemporáneo en las herramientas provistas por la ciencia y la tecnología continúa haciendo posible que el arte tome un nuevo significado y pase a nuevos contextos; no obstante, el videojuego no se trata de una de las formas tradicionales, como la literatura, la música, la pintura o el cine, sino más bien de una expresión creativa en donde confluyen elementos de todas las anteriores y que, además, ofrece como agregado distintivo un grado de interacción difícil de lograr de otra forma con el usuario, que pasa de ser un mero espectador a formar parte y tomar decisiones que determinan el devenir del juego (Ramos, 2014).

\section{VIDEOJUEGOS EN COLOMBIA: UNA INDUSTRIA EN CRECIMIENTO}

Con el fin de apreciar el contexto y la posición de la industria de los videojuegos en Colombia consideraremos dos aristas: por un lado, la del consumo y, por el otro, la del desarrollo, ambos al nivel nacional. Para ello se tienen en cuenta dos estudios que ofrecen datos al nivel mundial y al latinoamericano: el Global Market Report de 2015, realizado por la organización de investigación del mercado de videojuegos Newzoo y el estudio del profesor Raúl Katz denominado El ecosistema y la economía digital en América Latina.

En ese sentido, "en Latinoamérica el mercado de los videojuegos es estimado en US\$ 1.147 millones, aunque se caracteriza por un alto consumo de productos importados de Estados Unidos y Asia" (Katz, 2015, p. 215).

Por su parte, según el Global Market Report de octubre de 2015, Colombia se posicionó como el cuarto país latinoamericano en consumo de videojuegos (por debajo de Brasil, México y Argentina), y ocupó el puesto treinta y uno de cien, al nivel mundial, generando ingresos a la industria de US\$234,837,000 (Newzoo, 2015). Tal como se indica a continuación:

\section{Tabla 1. Ingresos por consumo de videojuegos en Latinoamérica}

\begin{tabular}{|c|l|c|}
\hline $\begin{array}{c}\text { Posición } \\
\text { Mundial }\end{array}$ & \multicolumn{1}{|c|}{ País } & $\begin{array}{c}\text { Ingresos totales en } \\
\text { US\$ }\end{array}$ \\
\hline 11 & Brasil & $1,148,902,000$ \\
13 & México & $1,195,456,000$ \\
22 & Argentina & $338,192,000$ \\
31 & Colombia & $234,837,000$ \\
40 & Chile & $170,081,000$ \\
\hline
\end{tabular}

Fuente: Newzoo's Global Market Report, 2015. 
Desde el punto de vista de ingresos por el desarrollo de videojuegos, la industria latinoamericana exporta gran parte de sus contenidos al exterior del continente, representando aproximadamente US\$237,5 millones, (Según Katz (2014, p. 215), "las estadísticas para este tipo de estimación son limitadas, pero permiten estimar un valor total para el sector, teniendo en cuenta las estadísticas de las firmas, programadores e ingresos de las empresas radicadas en América Latina.", liderando el sector Brasil, Argentina y México (Katz, 2015). En este contexto, en el 2014, Colombia contaba con 62 empresas dedicadas a la producción de videojuegos, con aproximadamente 1500 empleados y un volumen de ingresos estimado en US\$ 24,0 millones (Kazt, 2015).

Tabla 2. Ingresos por producción de videojuegos en Latinoamérica

\begin{tabular}{|l|c|c|c|c|}
\hline \multicolumn{1}{|c|}{ País } & empresas & $\begin{array}{c}\mathrm{N}^{\circ} \\
\text { empleados }\end{array}$ & $\begin{array}{c}\text { Ingresos } \\
\text { (millones de } \\
\text { dólares) }\end{array}$ & Año \\
\hline Brasil & 133 & 1133 & 98,7 & 2013 \\
\hline Argentina & 75 & 3000 & 55,0 & 2013 \\
\hline México & 93 & N.A. & 36,0 & 2013 \\
\hline Colombia & 62 & 1500 & 24,0 & 2014 \\
\hline Chile & 28 & 420 & 12,8 & 2014 \\
\hline Perú & 15 & N.A. & 6,0 & 2013 \\
\hline Uruguay & 12 & N.A. & 5,0 & 2013 \\
\hline Total & 418 & & 237,5 & \\
\hline
\end{tabular}

Fuentes: Argentina Games Developers Association, s. f. BNDES, 2014; Tomic, 2015; Marisca, 2014; Procolombia, 2014, como se citó en Katz, 2015.

Mientras que, a modo de comparación, en países como Francia (donde el desa- rrollo de videojuegos es la industria creativa más significativa para su economía), existen más de 500 empresas dedicadas al sector, entre ellas 242 estudios de desarrollo y 37 estudios de edición (Agence Française pour le Jeu Vidéo - AFJV, 2015), y con ingresos por la venta de videojuegos que alcanzan los 2,7 mil millones de euros (Gualbert, 2013).

Si bien Colombia no se ha posicionado en el escalafón de los tres primeros países productores de videojuegos en el mercado latinoamericano, no cabe duda de la existencia de una industria dedicada a la actividad, sobre todo porque algunos títulos nacionales han conseguido alta representatividad, entre ellos: Poltergeist: A pixelated horror (2014), un puzzle de horror desarrollado y editado por Glitchy Pixel, disponible en Steam, PS4 y PSVita; Story Warriors: Fairy Tales (2014), un puzzle educativo desarrollado por Below The Game, disponible para iOS y distribuido por Thumbstar Games y El Chavo Kart (2014), un juego de carreras desarrollado por Efecto Studios y distribuido por Slang, disponible en PS3, Xbox 360 y Android OS para dispositivos móviles Samsung.

\section{DEFINICIÓN, ELEMENTOS CONSTITUTIVOS Y PROCESO CREATIVO DEL VIDEOJUEGO}

La complejidad de su composición es la principal característica en la producción de un videojuego, lo que está determinado por su entramado creativo y técnico. Atendiendo a ello, diversos autores coinciden en sus definiciones al señalar los distintos elementos que forman parte de la obra, con el fin de hacer una deli- 
mitación precisa dirigida a resaltar dicha particularidad.

Esposito aporta la siguiente definición: "un videojuego es un juego que jugamos gracias a un aparato audiovisual y el cual puede estar basado en una historia" (2005, p. 6). De ello se puede abstraer que el videojuego está conformado básicamente por tres aspectos: el juego, visto como aquello que se juega, un sustantivo, y también como la acción del usuario que determina su devenir dentro de la arbitrariedad que le permite el sistema; el aparato audiovisual, que es el objeto que materialmente permite que exista el juego, que lo soporta; y la historia, conformada por todos los elementos narrativos del juego (como el contexto de los personajes, los diálogos, etc.) que está presente la mayoría de las veces para hacer la experiencia más interesante al jugador, aunque existen juegos que no contienen estos elementos, como es el caso de Tetris, donde no existe una historia de fondo que motive el juego.

Sin embargo, la definición anterior no tiene en cuenta el elemento que permite que el aparato audiovisual y el argumento se conjuguen de tal manera que ofrezcan interactividad y funcionalidad, es decir, que el videojuego pueda ser jugado. En ese sentido, Ramos (2014) entiende los videojuegos modernos como una combinación de elementos audiovisuales, por un lado, y de un software que gestiona técnicamente estos elementos y permite a los usuarios interactuar con los distintos componentes del juego, por el otro.

\begin{abstract}
Al contrario que otras industrias creativas, los videojuegos aprovechan elementos tanto del ámbito de la tecnología como de la creatividad artística, conjugando la expresión de la imaginación artística con la tecnología más avanzada. Los códigos informáticos (software) subyacentes a los juegos transforman las ideas en ricas expresiones de arte visual que cobran vida en diversos aparatos (hardware) - consolas, computadoras, tabletas y teléfonos inteligentes- (Greespan et al., p. 8).
\end{abstract}

Por lo tanto, Ramos et al. (2013) entienden certeramente lo que podría definirse como un videojuego, al expresar que son obras de autor complejas, pues contienen múltiples formas de arte, como la música, los guiones, la trama o argumento, vídeo, pinturas y personajes, que involucran interacción humana mientras se ejecuta el juego con un programa de computador en un hardware específico.

Así las cosas, teniendo en cuenta los conceptos anteriores, un videojuego puede ser definido como una obra interactiva que involucra elementos audiovisuales respaldados por un programa informático que hace posible su ejecución a través de un hardware.

En efecto, hoy en día los componentes creativos del videojuego son muchos, pero pueden ser clasificados, de acuerdo con Lipson \& Brain (citado por Ramos et al. 2013) en tres grupos: elementos de audio, elementos de vídeo y código informático. 
En ese orden, entre los elementos de audio encontramos composiciones musicales, grabaciones y efectos de sonido. A su vez, hacen parte de los elementos de vídeo: imágenes fotográficas, animaciones, ilustraciones y tipografías, capturas digitales de imágenes en movimiento, entre otras. Ambos grupos también pueden ser entendidos como elementos audiovisuales del videojuego. A su vez, el código informático o software, del cual se derivan los otros componentes informáticos del juego tales como el motor, el código auxiliar y los plug-ins, es la piedra angular de la interactividad y se encuentra compuesto por dos especies: el código fuente y el código objeto.

Así, el código fuente son las instrucciones escritas en lenguaje informático por el programador, de tal manera que pueden ser leídas por humanos, pues están escritas en un lenguaje de programación como Java o Python. El programador crea el código fuente para determinar la estructura del videojuego, imprimiendo su estilo y conocimiento al describir una serie de instrucciones que más tarde serán procesadas de forma automática por la computadora para crear el código objeto, que es el resultado de la conversión y descodificación realizadas por la computadora, y el cual está expresado en lenguaje binario y, por ello, solo puede ser entendido por la máquina que soporta el videojuego

Vemos, entonces, cómo en el proceso de creación y desarrollo de un juego de vídeo interviene un gran número de profesionales especializados, entre los que se encuentran el productor (que es quien supervisa la obra y el trabajo de todos los demás), los diseñadores (como los escritores, guionistas y diseñadores de interface), los artistas (que crean el aspecto visual del juego), los ingenieros de sonido (para los efectos de este tipo) y los programadores (que desarrollan el código), así como actores (de voz y movimiento), productores musicales y audiovisuales (Ramos et al., 2013).

\begin{abstract}
Si en la década de 1980, con el fin de crear un videojuego, la productora necesitaba el trabajo y el talento de solo unas pocas personas, las obras modernas requieren los esfuerzos conjuntos de decenas (a veces cientos) de empleados artísticos y técnicos antes de que el videojuego pueda alcanzar los estantes (Ramos et al., 2013, p. 9).
\end{abstract}

Es evidente, entonces, la existencia de una pluralidad de titulares de derechos de autor y conexos haciendo aportes al proceso creativo, razón por la cual pretender el registro del videojuego como una obra compacta significaría agruparlas también en su calidad de titulares de derechos, con todas las implicaciones en materia de derechos patrimoniales que ello implicaría.

\section{LA NATURALEZA JURÍDICA DEL VIDEOJUEGO}

Como ha sido evidenciado, la producción y preproducción del videojuego resulta tan complejo que necesariamente debe agrupar un gran número de elementos creativos (artísticos y tecnológicos) y na- 
turalmente de autores, de lo cual surge la pregunta por el videojuego como obra autónoma y, en consecuencia, por las titularidades que los involucrados en el proceso creativo deberían ostentar.

A continuación, realizaremos un análisis de tres categorías bajo las cuales podría pensarse una adecuación desde la legislación autoral vigente: el software, la obra multimedia y la obra cinematográfica.

\section{a. El videojuego como software}

El marco jurídico del derecho de autor en Colombia encuentra su base legal en la Ley 23 de 1982, que fue modificada y adicionada por la Ley 44 de 1993; sin embargo, en ninguna de ellas puede encontrarse una definición sobre la categoría de obras de soporte lógico, programas de ordenador o software, como sí fue caso de algunas otras clases de obras, como la cinematográfica.

Es necesario acudir al Decreto 1360 de 1989 por el cual se reglamenta la inscripción de soporte lógico (software) en el Registro Nacional del Derecho de Autor, para acercarnos al concepto de lo que se entiende por software en el ordenamiento jurídico colombiano. Así, el decreto en cita menciona que se entiende por programa de ordenador:

La expresión de un conjunto organizado de instrucciones, en lenguaje natural o codificado, independientemente del medio en que se encuentre almacenado, cuyo fin es el de hacer que una máquina capaz de procesar información, indique, realice u obtenga una función, una tarea o un resultado específico (Decreto 1360 de 1989, artículo 3-a).

En igual medida, la Comunidad Andina de Naciones (CAN) lo define en los siguientes términos:

Programa de ordenador (software): Expresión de un conjunto de instrucciones mediante palabras, códigos, planes o en cualquier otra forma que, al ser incorporadas en un dispositivo de lectura automática, es capaz de hacer que un ordenador -un aparato electrónico o similar capaz de elaborar informaciones-, ejecute determinada tarea u obtenga determinado resultado. El programa de ordenador comprende también la documentación técnica y los manuales de uso (CAN, Decisión 351 de 17 de diciembre de 1993, artículo 3).

De ambas definiciones se desprende con claridad la naturaleza utilitaria de este tipo de obras, es decir, que existen en razón a una finalidad práctica, sin que ello desvirtúe su valor como creación intelectual o implique la inexistencia de originalidad por parte del autor. El software tiene, por consiguiente, una vocación meramente funcional (lograr que una máquina haga algo, obtener un resultado), que podría generar conflicto si se aplicase a los juegos de vídeo, pues, como ya fue visto en el capítulo anterior, estos se nutren de múltiples creaciones autorales, muchas de las cuales constituyen formas de arte que mal podrían ser incluidas bajo la categoría del software. 
En legislaciones como la europea se dispone, en la motivación de su directiva sobre la protección jurídica de programas de ordenador, que "entre los criterios que deben utilizarse para determinar si un programa de ordenador constituye o no una obra original, no deben aplicarse los de carácter cualitativo o los relativos al valor estético del programa" (Dir. 2009/24/ CE del Parlamento Europeo y el Consejo, 2009) y, además, menciona el artículo 1, numeral 3 de la misma norma que "el programa de ordenador quedará protegido si fuere original en el sentido de que sea una creación intelectual propia de su autor. No se aplicará ningún otro criterio para conceder la protección".

Más allá, se sabe que el objeto susceptible de protección jurídica por derecho de autor son las expresiones concretas del intelecto, y no las ideas, es decir, las obras, no la finalidad que ellas pretenden. Bien menciona la ley sobre derecho de autor que:

Las ideas o contenido conceptual de las obras literarias, artísticas y científicas no son objeto de apropiación. Esta Ley protege exclusivamente la forma literaria, plástica o sonora, como las ideas del autor son descritas, explicadas, ilustradas o incorporadas en las obras literarias, científicas y artísticas (Ley 23 de 1982, Art. 6).

En ese sentido,

Se ha entendido que en principio el aspecto práctico de un programa de computador, su aplicación o su funcionalidad no son objeto de protección por el derecho de autor, toda vez que la función de un programa o software es la misma idea no protegible de la obra. (Centro de Arbitraje y Conciliación -Cámara de Comercio de Bogotá, 2006)

De lo anterior se puede abstraer la existencia de una contradicción en relación, no solo a por qué proteger los juegos de vídeo como programas de ordenador, sino por qué proteger los programas de ordenador por derecho de autor, si de las definiciones legales está claro que la utilidad o aplicación, esto es, la idea que los sustenta es su cualidad determinante.

En efecto, la protección del software por las vías del derecho de autor, aunque es la tendencia que se ha generalizado normativamente en el mundo, no es la única planteada en la doctrina, pues hay quienes sostienen que una protección más eficiente podría ser lograda por el otorgamiento de patentes de invención o modelos de utilidad, mediante secretos industriales, e incluso a través de regímenes sui generis (Ruiz, 2009), ni por la jurisprudencia, teniendo en cuenta el caso State Street Bank \& Trust and Co. versus Signature Financial Group Inc., proferida en 1998 por la Corte del Circuito Federal de los Estados Unidos, que determinó que un algoritmo matemático, la base de un software, puede ser patentable siempre y cuando produzca un resultado concreto, útil y tangible.

No obstante, a la fecha el software es protegido en Colombia meramente como la descripción de una serie de algoritmos 
en lenguaje codificado, es decir, como una obra literaria (expresada a través de letras, números o signos) que posee necesariamente un valor funcional que se superpone a cualquier otra calidad que pueda serle atribuida y, aunque es cierto que eventualmente el creador de un programa de ordenador no lo hará para que sea bello sino para que cumpla una función, el producto final (la obra) contendrá indefectiblemente dejos de una voluntad creativa expresada en forma de decisiones, como el conjunto de palabras empleadas para su descripción, lo cual denota, en efecto, la impresión de un sello personal (originalidad) por parte del creador.

Ahora bien, con respecto a la titularidad de los derechos se abstrae del Decreto 1360 de 1989 la existencia de un autor que ostente los derechos que le corresponden a su naturaleza según la Ley 23 de 1982 y un productor que sea dueño de derechos conexos sobre la obra. Sin embargo, ¿quién es el creador del software? La persona que desarrolla el programa, naturalmente, que usualmente es distinta de quien diseña los personajes o los paisajes, para citar un ejemplo, con lo cual surge otro problema frente a la adecuación de los videojuegos en esta categoría.

Queda entonces la pregunta por los aspectos estéticos del juego de vídeo en caso de ser protegido como obra de soporte lógico, pues estos forman parte de la obra vista como una unidad y se constituyen en un factor que brinda verdadero mérito artístico y, en ocasiones, un sello distintivo al juego (pensemos en los personajes de Final Fantasy, los paisajes de The Elder Scrolls o la banda sonora de Destiny).

Este tipo de elementos conformados por secuencias de imágenes y sonidos no son el centro alrededor del cual gira la tutela del derecho de autor en la categoría de software, sino que resultarían más bien accesorios a ella; es por ello que resulta necesario plantear un esquema de protección distinto a los programas de ordenador para este caso.

\section{b. El videojuego como obra multimedia}

Podemos definir, a falta de una norma jurídica precisa, las obras multimedia como una composición de distintos géneros de elementos creativos que son cohesionados en un formato digital mediante el cual les es permitido algún grado de interacción entre ellos.

Cuando se trata de los elementos creativos de los cuales se nutre una creación multimedia, puede hacerse referencia a múltiples categorías de obras protegidas por derecho de autor, como las literarias, las imágenes fijas o en movimiento y obras musicales, mientras que el formato digital en el cual están soportadas es, esencialmente, un archivo de información capaz de ser descifrado por un software que traduce todo el contenido (de imágenes, sonido, vídeo, etc.) a partir de una serie de números binarios.

Es por ello que cuando se emplea el término de obra multimedia en verdad no se está refiriendo a varios medios en los que 
esté contenida la creación, sino más bien a la diversidad de formas de expresión a partir de las cuales esta es cohesionada (Ruiz, 2009). De tal forma, encontramos que un juego de vídeo podría ser fácilmente encuadrado hasta este punto como una obra multimedia, pues sus características básicas corresponden, sobre todo si se tienen en cuenta conceptos de multimedia como el de Ruiz, que lo define como:

La combinación de textos, imágenes reales o virtuales, animación y sonidos, los cuales interactúan de manera armónica gracias a un programa de ordenador (software maestro), que hace posible que el usuario logre una interface con todos y cada uno de elementos, interactuando con ellos y dejando de ser un espectador pasivo frente a la obra, para constituirse en una parte integral de ella e infundir en su entorno (2009, p. 314).

Sin embargo, la razón por la cual no existe en Colombia una norma jurídica que estipule qué es el multimedia es que este tipo de creaciones no están concebidas como una categoría de obra independiente o autónoma dentro del ordenamiento jurídico vigente; de ahí que la protección se brinde más bien mediante una desfragmentación de las partes, y no al conjunto en sí mismo.

La Dirección Nacional de Derecho de Autor ha mencionado que:

La multimedia no encaja dentro del concepto de obra, por lo tanto, por sí misma no está pro- tegida por el derecho de autor, no obstante, todas las obras que incorpora -literarias o artísticas, como son canciones, dibujos, fotografías y textos escritos-además del software sobre el cual se estructura la interactividad, son objeto de protección por parte de la legislación autoral (Dirección Nacional de Derecho de Autor, 2007).

Razón por la cual, de considerarse el vi deojuego como una creación multimedia en el marco colombiano, todavía nos estaríamos enfrentando a la pregunta de cómo lograr una protección que lo tome como un todo, como una obra única, y no como la sumatoria de varios tipos de obra.

Esta tradición, que comparte Colombia en la actualidad con países como los Estados Unidos de América, se traduce, además, en un gran número de trámites de registro que deben ser adelantados ante la autoridad competente para lograr un blindaje jurídico efectivo: uno por cada tipo y cada obra contenidos en el multimedia; además, que por cada tipo de obra pueden existir otros tantos titulares de derechos de autor y conexos. Lo anterior implica, en un Estado como el nuestro, un desgaste de recursos de la Administración Pública que bien podrían ser invertidos en cubrir otras necesidades importantes si tan solo el trámite de registro del multimedia pudiera iniciarse mediante la radicación de una sola solicitud.

Además, es menester reflexionar sobre el papel que cumple la Dirección Nacional 
de Derecho de Autor como autoridad nacional en materia de registro y promoción de los derechos de autor, que, teniendo en cuenta que el legislador Colombiano no establece otros criterios para reconocer una creación intelectual como obra que el de la originalidad y la susceptibilidad de ser divulgada o reproducida, mal podría estar haciendo al negarle la calidad de tal a un objeto que a todas luces cumple con tales requisitos.

\section{c. El videojuego como obra cinematográfica}

Aunque una película y un videojuego son dos tipos de arte distintos, sus similitudes podrían resultar útiles para superar el bache de la desfragmentación de la obra, planteado por el multimedia, y del predominio del programa de ordenador y la desestimación de los elementos artísticos, planteados por el registro como software.

Lo que se pretende sustentar en este acápite es la posible aplicación de una analogía para lograr que el juego de vídeo sea registrado como una obra en colaboración, "producida por un grupo de autores, por iniciativa y bajo la orientación de una persona natural o jurídica que la coordine, divulgue y publique bajo su nombre" (Ley 23 de 1982, Art. 8- D).

En el caso de las obras cinematográficas, la Ley 23 de 1982 dispone en el artículo 95 que los titulares de derechos sobre este tipo de obra son: el director, el autor del guion o libreto, el autor de la música y el dibujante o dibujantes, cuando se trata de un diseño animado. Si se aplica una analogía para los juegos de vídeo, podría el desarrollador del software, en tanto esta es una obra literaria, ser asimilado a un guionista o libretista, especificando en el trámite de registro la naturaleza de código informático, mientras los demás titulares podrían permanecer más o menos iguales en ambos casos.

Además, el artículo 94 de la Ley de Derecho de Autor señala que "sin perjuicio de los derechos de los autores de las obras adaptadas o incluidas en ella, la obra cinematográfica será protegida como una obra original", lo cual indica que si bien para su creación participan varios autores que realizan aportes originales al proyecto, ellos forman una sola obra independiente con un registro único ante la Dirección Nacional de Derecho de Autor, algo muy parecido a lo que estamos tratando de lograr con los videojuegos.

De tal forma, al momento de la creación del juego, se estaría trabajando en un plano de igualdad entre todos los creativos, a los cuales se les permite mantener la titularidad de los derechos sobre sus propias contribuciones, aun cuando es el director o realizador quien ostenta la titularidad sobre el conjunto. Al respecto menciona la ley sobre los derechos morales de autor, es decir los que protegen la paternidad, la publicación, la integridad, la modificación y el retiro de la obra, que:

El director o realizador de la obra cinematográfica es el titu- 
lar de los derechos morales de la misma, sin perjuicio de los que corresponden a los diversos autores, artistas, intérpretes o ejecutantes que hayan intervenido en ella, con respecto a sus propias contribuciones (Ley 23 de 1982, Art. 99).

En relación con los derechos patrimoniales sobre la obra, que protegen la reproducción, transformación y comunicación al público, estos serán reconocidos "salvo estipulación en contrario a favor del productor" (Ley 23 de 1982, Art. 98). No obstante, la misma ley señala que "cada uno de los coautores de la obra cinematográfica podrá disponer libremente de la parte que constituya su contribución personal para utilizarla por un medio distinto de comunicación, salvo estipulación en contrario" (Art. 101).

Lo anterior implica, por ejemplo, que los diseñadores de personajes icónicos como Mario, de la franquicia de Nintendo, serían tenidos como coautores del juego, y no únicamente como artistas empleados de la compañía. De tal forma podemos sustentar que, aun cuando no existe una legislación específica, el aparente vacío con respecto a la tutela de los juegos de vídeo podría ser superado por la aplicación análoga de las disposiciones sobre obras cinematográficas situadas dentro de la misma legislación autoral.

\section{ADECUACIÓN EN DERECHO COMPARADO}

Los elementos creativos que componen un videojuego son de diversa índole; por lo tanto, al momento de plantear qué tipo de protección jurídica requieren es importante delimitar su propia naturaleza teniendo en cuenta cada uno, hasta adecuar el producto final en la categoría que proporcione una protección más eficaz. Sin embargo, no existe consenso mundial acerca de la naturaleza de estas obras complejas, de lo cual se desprende el debate que se libra en los escenarios jurídicos de cada Estado donde se intenta regular la materia.

Teniendo en cuenta la falta de uniformidad jurídica que se manifiesta en el ámbito mundial, se presenta en esta disertación un análisis comparativo, teniendo en cuenta aspectos relevantes tales como el marco jurídico, la clasificación legal del juego de vídeo, la titularidad y la transferencia de los derechos, basado en el estudio encargado por la Organización Mundial de la Propiedad Intelectual (OMPI) denominado The Legal Status of Video Games: Comparative Analysis in National Approaches, donde se evidencian dichas dicotomías.

Para abordar el análisis se tomarán como referentes los siguientes países: Estados Unidos, Japón, Francia y Argentina, atendiendo a su trascendencia cultural y económica en el sector.

\subsection{Estados Unidos}

\section{- Marco jurídico y clasificación legal}

La Ley estadounidense de Derechos de Autor de 1978 no establece una clasificación expresa para los video- 
juegos. En ese sentido, Ramos et al. (2013) señalan que en la práctica se registran como obra audiovisual o como programa informático, dependiendo de los elementos creativos predominantes del juego de vídeo, siempre y cuando se trate de obras originales fijadas en cualquier medio de expresión tangible, ya sea digital o analógico, con el fin de ser reproducidos o percibidos.

\section{- Titularidad y transferencia de los derechos}

En principio, el editor y el productor son los titulares de los derechos patrimoniales, salvo que se pacten acuerdos contractuales donde los autores y empresas desarrolladoras puedan tener parte en la titularidad de estos. De hecho, toda persona que haga contribuciones originales a la obra puede ser autor; sin embargo, si la contribución es producto de una relación de subordinación laboral, la autoría estará en cabeza del empleador (Ramos et al, 2013; Oficina de Derechos del Autor de los Estados Unidos, 2008).

Al igual que en el Estado colombiano, los derechos patrimoniales pueden ser transferidos total o parcialmente. Tal como refieren Ramos et al, (2013), si la obra es producto de una relación laboral, para la transferencia de los derechos basta con un acuerdo escrito y firmado por las partes. Para los demás casos, la transferencia se hace por medio de contratos de licencia o cesión.

\subsection{Japón}

\section{- Marco jurídico y clasificación legal}

La Ley de Derechos de Autor japonesa (Ley 48 de 1970) no dispone clasificación expresa que establezca la naturaleza legal y precisa de los videojuegos. No obstante, la jurisprudencia japonesa, a través de los precedentes establecidos por la Corte Suprema de dicho país, ha reconocido estas creaciones como obras cinematográficas, teniendo en cuenta que los videojuegos tienen una forma de expresión similar a aquellas (Ramos et al, 2013); sin embargo, no se deja de lado la clasificación distributiva, pues también pueden ser protegidos como programas informáticos.

\section{- Titularidad y transferencia de los derechos}

Al igual que en la mayoría de las jurisdicciones, se presume que el titular de los derechos de autor es la persona cuyo nombre aparezca en el original de la obra o en el lugar de su distribución (Copyright Research and Information Center-CRIC-, 2016). Por otro lado, el productor de la obra figurará como autor, tal como sucede con las obras cinematográficas, al igual que el editor (Ramos et al; 2013).

En el mismo sentido, cualquier transferencia de derechos de autor, ya sea parcial o total, que estén en cabeza del empleador, puede realizarse mediante un acuerdo verbal o escrito (CRIC, 
2016). En los demás casos se efectuará a través de contratos de licencia o cesión.

\subsection{Francia}

\section{- Marco jurídico y clasificación legal}

El Código de Propiedad Intelectual de Francia (CPI) de 1992 no dispone un régimen especial para los videojuegos. Sin embargo, un sector de la jurisprudencia francesa considera que los videojuegos son una obra compleja que no puede ser reducida al programa informático (Cardella, 2011) y, a su vez, deben ser considerados los demás componentes de la obra, que deberán ser protegidos atendiendo su naturaleza particular (Cour de Cassation de France, 2009), es decir, su clasificación es distributiva.

\section{- Titularidad y transferencia de los derechos}

Cualquier persona natural que contribuya, total o parcialmente, a la creación de un videojuego puede ser calificada como autor, siempre que su contribución sea creativa y original, entre ellas: autores, productores, editores, diseñadores de sonido, diseñadores de arte, guionistas, y programadores (Ramos et al; 2013). Al igual que en otras jurisdicciones, si la obra es producto de una relación laboral, el empleador será el titular de los derechos.
En el artículo 113-9 del CPI de Francia se presume, salvo disposición contraria, que la transferencia de derechos será automática cuando la obra sea un software creado en virtud de un contrato laboral y, en consecuencia, el empleador será el único facultado para ejercer los derechos patrimoniales sobre el programa informático, mientras que si se trata de una obra audiovisual se presumen como autores, salvo pacto en contrario: al autor del escenario, al autor de la adaptación, al guionista, al compositor musical, y al director, y a su vez, también se presume al productor como el titular de los derechos patrimoniales (Ramos et al; 2013).

\subsection{Argentina}

\section{- Marco jurídico y clasificación legal}

En el Régimen Legal de Propiedad Intelectual o Ley 11.723 (1933), modificada por la Ley 26.570 (2009), no hay clasificación expresa para los juegos de vídeo como un todo. Sin embargo, "los videojuegos son entendidos, básicamente, como software con características especiales" (Ramos et al; 2013, p. 12); es decir, se trata de un programa informático que, a su vez, incluye otros elementos creativos.

\section{- Titularidad y transferencia de los derechos}

La titularidad de los derechos de autor está en cabeza de los autores, editores, productores, y demás personas que hagan aportes creativos y 
originales a la obra. Cuando la obra se haga en virtud de un contrato laboral, la titularidad de los derechos estará en cabeza del empleador, y la transferencia de los derechos debe hacerse a través de contrato escrito (Ramos et al; 2013).

El artículo 4 del régimen de propiedad intelectual argentino presume que la titularidad de los derechos se considerará propiedad del estudio desarrollador del videojuego, a menos que se exprese lo contrario. Mientras, cuando se realice la obra en virtud de un contrato laboral, Ramos et. al (2013) indican que será suficiente una cláusula expresa que disponga la transferencia de los derechos de autor del empleador al trabajador

\section{CONCLUSIONES}

Para la creación de un videojuego se suman varios elementos creativos, tales como imágenes, animaciones, composiciones musicales y literarias (código fuente y objeto), razón por la cual es importante reconocer que proteger los juegos de vídeo únicamente como software fragmenta la obra, es decir, le niega su complejidad restando importancia al resto de sus componentes creativos, mientras que una protección que los tenga como obras audiovisuales o multimedia les niega, hasta la fecha, la posibilidad de mantenerse unidos como una sola creación. Es por ello que encuadrar el juego de vídeo como un todo dentro de una sola categoría de derecho de autor se mantiene como un reto en el derecho a la actualidad.
Tal como se evidenció en el capítulo de derecho comparado, en ninguno de los países estudiados existe un régimen jurídico especial para proteger los videojuegos como una obra independiente de las categorías de programa informático, obra multimedia o cinematográfica (esta última reconocida judicialmente).

En Estados como Francia y EE. UU. se ha propendido por efectuar una clasificación distributiva, es decir, no considerar que el videojuego es una sola obra, sino acceder al registro individual de cada uno de sus aportes: registrar el código como software, las composiciones musicales y fotografías como obras de esos tipos, etc. Para evitar ese desgaste, en ordenamientos jurídicos como el japonés la jurisprudencia ha acudido a una analogía que encuadra a los videojuegos como obras cinematográficas, sin que quede resuelta la particularidad sobre el código, mientras en Argentina, estando también ausente una normativa específica, este tipo de obras son entendidas únicamente como software. En tal sentido, la adopción de una clasificación distributiva no resuelve el problema en la práctica, pues los sujetos implicados en la producción de esta obra necesitan un modelo único que les ofrezca seguridad jurídica al momento de registrarla y protegerla, ni resulta eficiente por el desgaste de tiempo y recursos que ella implica.

Dicha solución puede lograrse, bien aplicando la regulación autoral sobre obras cinematográficas por analogía, que como fue visto ofrece un modelo que supera la desfragmentación innecesaria de la obra 
$\mathrm{y}$, en consecuencia, protege los derechos morales y patrimoniales de todos los sujetos implicados en su proceso creativo, ya sea el desarrollador de software, los músicos o los diseñadores y dibujantes, o bien, mediante el registro de un tipo de obra.

Al respecto, el reconocimiento de una obra específica denominada juego de vídeo es posible teniendo en cuenta que, en primer lugar, el listado de obras que ofrece el legislador es meramente enunciativo, no taxativo y, además, el registro proferido por la autoridad administrativa en materia de derecho de autor no crea derechos, como sí sucede en el caso de los bienes de propiedad industrial, aun cuando este constituye un medio probatorio idóneo para acreditar los derechos sobre la obra, y en ese sentido, el videojuego se encuentra protegido como un todo aun cuando la Dirección Nacional de Derecho de Autor no lo reconozca en su plataforma web de trámite de solicitudes.

\section{REFERENCIAS BIBLIOGRÁFICAS}

Agence Française pour le Jeu Vidéo. (2015). Annuaires des sociétés de jeux vidéo. AFJV. Recuperado de: http://www.afjv.com/ annuaires_ jeux _ video.php

Cardella, B. (2011). Le droit des jeux vidéo, de la virtualité à la réalité juridique. Université du Sud Toulon Var. Recuperado de: https://tel. archives-ouvertes.fr/tel-00658291

Centro de Arbitraje y Conciliación-Cámara de Comercio de Bogotá, Laudo del Tribunal de Arbitramento de AS Colombia LTDA c. Informática y Gestión S. A. de 17 de octubre de 2006.
Comunidad Andina de Naciones. Decisión 351 de 17 de diciembre de 1993, que establece el Régimen Común sobre Derecho de Autor y Derechos Conexos. Gaceta Oficial de la Comunidad Andina 145, 21 de diciembre de 1993.

Copyright Research and Information Center. (2016). Copyright Law of Japan. Recuperado de: http://www.kidscric.com/english/clj/ index.html

Cour de Cassation de France, première chambre civile, arrêt 732 du 25 de juin, 2009.

Decreto 1360 de 1989 [Raúl Orjuela Bueno, Ministro de Gobiernol, Por el cual se reglamenta la Inscripción del Soporte Lógico (software) en el Registro Nacional del Derecho de Autor, 23 de junio de 1989.

Dirección Nacional de Derecho de Autor, concepto emitido el 24 de septiembre de 2007, radicado 1-2007-23558.

Donaire, F. J. y Planells, A. J. (2012). La protección jurídica de los derechos de autor de los creadores de videojuegos: "Statu quo" perspectivas y desafíos. Madrid: Trama.

Esposito, N. (2005). A Short and Simple Definition of What a Videogame Is. DiGRA 2005: Changing Views: Worlds in Play, 2005 International Conference http://summit.sfu. ca/item/258

Greespan, D., Boyd, S. G., Purewall, J. (2014). Los videojuegos y la PI: Perspectiva mundial. Revista de la OMPI, (2): 7-11.

Greespan, D., Boyd, S. G., Purewal, J. y Datum, M. (2013). Mastering the game: Business and Legal Issues for Video Game Developers. Recuperado de: http:// www.wipo.int/publications/es/details. jsp?id $=3233$ \&plang $=E N$

Gualbert, B. (2013). Les enterprises franciliennes du jeu vidéo, compétentes et dynamiques 
mais fragiles sur un marché mondialisé. Centre Régional D'Observation du Commerce, de l'Industrie et de Services (158). Recuperado de: https://goo.gl/MKmW96

Jewel, C. (2012). Los videojuegos: arte del siglo XXI. Recuperado de: http://www.wipo.int/ wipo _ magazine/es/2012/04/article _ 0003. html

Katz R. (2015). El ecosistema y la economía digital en América Latina. Recuperado de: https:// goo.gl/CTVlj5

Ley 23 de 1982. [Congreso de la República] Sobre Derechos de Autor, 28 de enero de 1982

Ministerio de Tecnologías de la Información y las Telecomunicaciones. (2015). Comportamiento del sector TIC en Colombia. Recuperado de https://goo.gl/qfBfb0

Newman, J. (2004) Videogames. Routledge Introductions to Media and Communications. Londres y Nueva York: Routledge.

Newzoo. (2015). Top 100 Countries by Game Revenues. Recuperado de: https://newzoo. com/insights/rankings/top-100-countriesby-game-revenues/

Oficina de Derechos del Autor de los Estados Unidos. (2008). Fundamentos del Derecho de Autor. Biblioteca del Congreso de los
Estados Unidos. Recuperado de https://www. copyright.gov/espanol/

Procolombia. (2014). Colombia Bring IT on. Gobierno de Colombia. Recuperado de: http://www.procolombia.co/noticias/bringit-la-campana-para-impulsar-industria-detecnologia-colombiana-en-el-mundo

Rabin, S. (Ed.). (2010). Introduction to Game Development. Boston: Course Technology.

Ramos, A. (2014). Videojuegos: ¿programas informáticos u obras creativas? Revista de la OMPI, (4): 25-28.

Ramos, A., López, L., Rodríguez, A., Meng, T., y Abrams, S. (2013). The Legal Status of Video Games: Comparative Analysis in National Approaches. Recuperado de: https://goo. gl/Sla8wZ

Ruiz, W. R. (2009). Propiedad intelectual en la era de las tecnologías de la información y las comunicaciones. Bogotá: Temis SA.

Unión Europea. Directiva 2009/24/CE del Parlamento Europeo y el Consejo, de 23 de abril de 2009, sobre la protección jurídica de programas de ordenador. Diario Oficial de la Unión Europea L 111, 5 de mayo de 2009, pp. 16-22. 